



\section{A cultura e o Design social}

Partindo de uma visão antropológica para melhor entendemos alguns conceitos estabelecidos na sociedade, podemos definir cultura como uma rede de significados, que cria sentidos ao mundo que cerca um indivíduo e que engloba um conjunto de diversos aspectos, como valores, crenças, leis, línguas, etc. Seguindo estes critérios podemos afirmar que é impossível um indivíduo não ter cultura, pois desde que nascemos estamos involuntariamente inseridos em um contexto social seja ele qual for.

Observando o Design como um processo criativo onde a compreensão supera a de tê-lo somente como um lampejo artístico, ou como uma ação racional, requer diversas variáveis relacionadas ao aspecto cultural, para se desenvolver algo que atenda as necessidades materiais e culturais da sociedade. Portanto encarar o Design como uma atividade cultural, é assumir seus valores, lembrando que o Design é uma atividade multidisciplinar, que buscará junto com outras áreas do conhecimento maneiras de melhor desempenhar seu trabalho, gerando recursos a favor da sociedade.

Nesse contexto de cultura e as constantes transformações na sociedade abrem caminhos para o surgimento de novas questões para sustentabilidade, meio ambiente e inclusão social. Esse tipo de questionamento atinge não só as áreas de economia e política, mas também a área de Design. É importante que o Designer esteja apto a trabalhar e a entender essas transformações, refletindo assim no Design social. Vale a pena ressaltar, conforme Klaibert Miranda (2008, s.I.):
É preciso deixar claro, no entanto, que o Design social nada tem a ver com assistencialismo, as ações desta vertente do design têm como foco, transformar situações de desigualdade social e tecnológica, ofe- recendo através do design, recursos para que estas barreiras sejam superadas, gerando oportunidades de desenvolvimento com resgate da cidadania e a dignidade.

Não podemos falar de Design cultural sem mencionarmos, comunidades, afinal os dois estão diretamente ligados. O Designer procura comunidades carentes onde haja uma necessidade iminente de ajuda para que possa haver um desenvolvimento não somente social, mas industrial, e é por meio da cultura que buscaremos ferramentas junto com a comunidade para ao menos tornarmos visíveis os tipos de manifestações que correm dentro das comunidades para os outros nichos sociais, pela utilização de ícones e signos.

Considerando o Designer um agente cultural, que trabalha ao lado de diversos outros profissionais de outras áreas do conhecimento, podemos avaliar o impacto que pode-se causar perante um profissional que ignora ou desconhece as peculiaridades 
que constituem certa identidade regional e, ao mesmo tempo, ignora os significados sociais ali instituídos. Seu papel como agente formador de cultura é diagnosticar formas de Design que trabalham junto com a sociedade, dando suporte sem interferir em seus conceitos. Para isso ele precisa estar ciente de que a identidade se constituiu ao longo do tempo por meio de relações sociais das pessoas e suas comunidades.

Assim sendo, o Design social tem como foco os projetos que visem a transformação de um determinado grupo social e que auxiliem esse grupo no resgate da cidadania e da cultura. $O$ Designer necessita ter em mente que seus projetos podem e devem contribuir para a sociedade provocando mudanças comportamentais que implicarão em uma responsabilidade social onde, muitas vezes, não paramos para pensar, mas envolvem nosso processo de criação, visando otimizar o desempenho referente ao que estamos trabalhando.

\subsection{Análise da contribuição do Design social para a comunicaçáo de projeltos culturrais}

O Design social possibilita a estruturação de projetos sócio-culturais que não possuem um trabalho de impacto. Por mais que o trabalho desenvolvido por esses projetos culturais possuam conteúdo relevante, cabe ao Designer trabalhar isso de forma que esse projeto ganhe visibilidade, dando maior perspectiva no futuro.

Um dos projetos culturais que nos chamaram a atenção no decorrer da pesquisa, além do estudo de caso que será relatado adiante, foi o JAMAC - Jardim Miriam Arte Clube, que tem por finalidade lutar contra a exclusão social, trabalhando com os moradores do bairro Jardim Miriam aspectos como noções de cidadania, buscando transformar o bairro em um centro de trabalho da arte social, fazendo com que artistas possam cultivar sua criatividade ao máximo e explorando de maneira ativa o potencial transformador da arte. Seu objetivo é, com isso, tentar melhorar a qualidade de vida do bairro, oferecendo-lhes uma opção de lazer e formas de capacitar seus moradores em suas habilidades artísticas. Seus trabalhos são aplicados em paredes, praças, muros de museus, muros de galerias, locais de passagem, ou seja, em paredes e muros externos, as pinturas de paredes são projetos prioritários do JAMAC, como podemos ver logo abaixo.

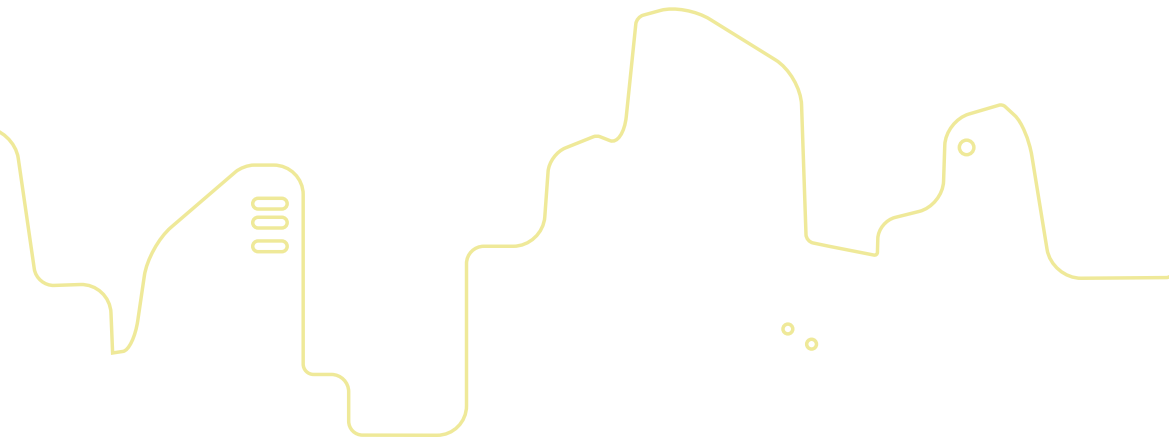




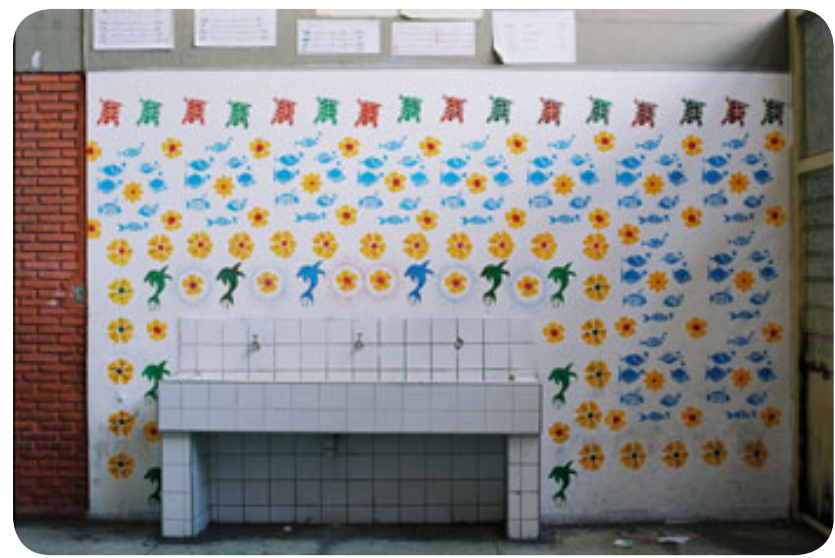

Figura 71. Aplicação dos grafismos desenvolvidos pelo JAMAC nas paredes. Fonte: Catálogo JAMAC - Jardim Miriam Arte Clube - 2007

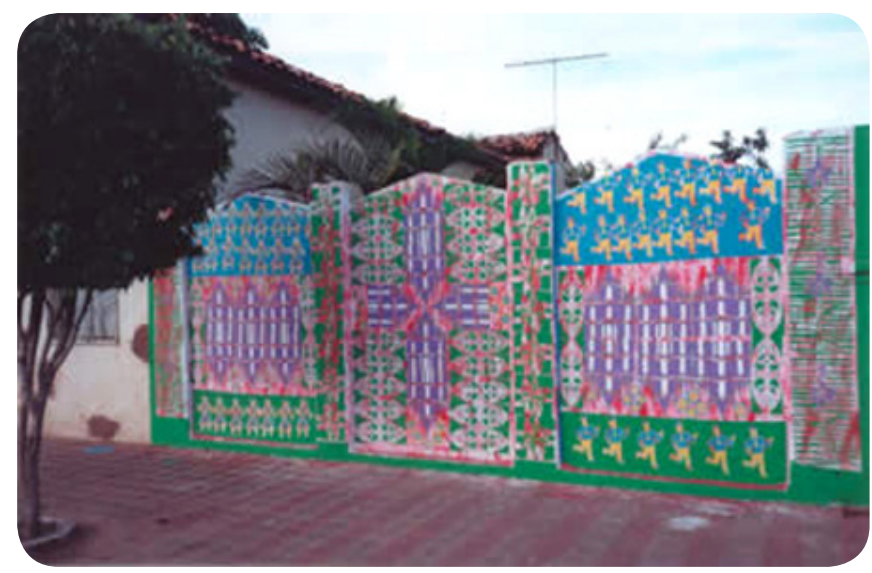

Figura 72. Aplicação dos grafismos desenvolvidos pelo JAMAC em um mural.

Fonte: Catálogo JAMAC - Jardim Miriam Arte Clube - 2007

Após uma breve análise do que é o projeto Jardim Miriam Arte Clube, podemos apontar a relevância do Design para projetos culturais. Juntamente com Mônica Nador, pintora, desenhista e gravadora, formada em Artes Plásticas pela Fundação Armando Álvares Penteado - FAAP, São Paulo, em 1983, idealizadora e coordenadora do projeto JAMAC e que tem como assistente Paulo Meira, um artista plástico e Designer que é responsável pela concepção dos projetos gráficos, é ensinar as técnicas de pinturas aplicadas nas paredes para as pessoas da comunidade. O Designer neste caso, influencia 
na divulgação do projeto e na forma como ele será apresentado para o público, tanto comercialmente quanto culturalmente, agregando valor a algo que até então não havia sido discutido. Lembrando que o Designer não trabalha neste âmbito sozinho, ele precisa inserir em sua dinâmica o grupo para poder adquirir conteúdo que dará significados por meio destas relações estabelecidas, podendo depois de uma análise traçar modos e metodologias para trabalhar com estas comunidades sem perder o foco principal do projeto, como é o caso do JAMAC.

Outro ponto que nos chamou a atenção para o projeto JAMAC foi a relação dos moradores de Santo André, São Paulo, para com o grupo, que além de incentivar os trabalhos artísticos dos moradores por meio de "workshops", promoveu um encontro mensal em seu barracão chamado de café filosófico, onde debatem temas como arte, graffiti, política, entre outros temas e discutem a relação de como o trabalho deles influencia no bairro e que dimensão esse projeto tomou. 